\title{
Yatan Hastaların Bakım Memnuniyetlerinin Değerlendirilmesi: Kamu Hastanesinde Bir Uygulama
}

DOI: 10.26466/opus.519588

\author{
Çağrı Köroğlu* - Hüseyin Önlem Ersöz - Aslı Çayan*** Sultan Kılıç*** \\ * Doç.Dr., Aydın Adnan Menderes Üniversitesi, Nazilli IİBF, Nazilli / Aydın / Türkiye \\ E-Posta: cagrikoroglu@hotmail.com ORCID:0000-0003-4073-1847 \\ ** Öğr.Gör.Dr., Aydın Adnan Menderes Üniv., Nazilli Sağ. Hiz. MYO, Nazilli/Aydın/Türkiye \\ E-Posta: hoersoz@adu.edu.tr ORCID:0000-0002-6604-1783 \\ *** Öğr.Gör., Aydın Adnan Menderes Üniv., Nazilli Sağ. Hiz. MYO, Nazilli/Aydın/Türkiye \\ E-Posta: asli.cayan@adu.edu.tr ORCID:0000-0002-5896-0341 \\ **** Öğr.Gör., Aydın Adnan Menderes Üniv., Nazilli Sağ. Hiz. MYO, Nazilli/Aydın/Türkiye \\ E-Posta: $\underline{\text { sultankilic@adu.edu.tr } \quad \text { ORCID:0000-0002-6651-4894 }}$
}

\section{$\ddot{O} z$}

Türkiye'de sağglk sektörü hızla değişmekte ve büyümektedir. Sağglı sektörünün önemli bir parçası olan hastanelerin günün şartlarına göre yönetilmesi zorunluluk haline gelmiştir. Çünkü Türkiye'de toplumun her kesimi tarafindan sağhlğa verilen önem her geçen gün artmaktadır. Bu durum hastanelerin sağlık hizmetlerinde kalitenin yükselmesini sağlasa da bir takım sorunları da beraberinde getirmektedir. Türkiye'de kamu hastanelerinin kaynağının sorunları temel olarak yönetim ve organizasyon eksikliğidir. Bu yönetim sorunlar hizmet kalitesinde ve hasta memnuniyetinde boşluklara neden olmaktadır. Yatan hasta memnuniyeti araştırmalarının çoğunda, sağllk personelinden memnuniyet, sağllk personeline güven, hasta gizliliği, personelin dürüstlü̆g̈̈, nezaket bilgisi, hastane genel temizliği ve otel hizmetleri gibi boyutlar tartışılmaktadır. Bu çalışmanın amacı bir kamu hastanesinde yatakta tedavi hizmetleri gören hastaların bakım memnuniyetlerini değerlendirmek ve bazı öneriler sunabilmektir. Çalışmanın evrenini kamu hastanesinde yatan hastalar oluşturmaktadır. Çalışmanın veri toplama yöntemi yatan hastalarla mülakat, soru sorma ve hazır verilerden yararlanmadır. Elde edilen veriler istatistik paket programı aracılığıyla analiz edilmiştir. Çalışmaya Nisan 2018'de Nazilli kamu hastanesinde yatarak tedavi gören 164 hasta dahil olmuştur. Çalışma sonuçlarına göre katılımcıların genel bakım memnuniyet algısı ile yaş grupları ve çalışma durumları arasında anlamlı farklılık olduğu söylenebilir.

Anahtar Kelimeler: Sağglı Sektörü, Kamu Hastanesi, Sağllk Hizmetleri, Yatan Hasta, Sağglk Yönetimi 


\title{
Healthcare Satisfaction Evaulations of Inpatients: A Practice in Public Hospital
}

\begin{abstract}
The health sector in Turkey has been rapidly changing and growing. It has become a necessity for hospitals, which is an important part of the healthcare sector, to be managed according to the circumstances of the day. Because the importance of health given by all segments of society in Turkey has been raising, day by day. Although this helps to increase the quality of the health care services of the hospitals, it also brings with it a number of problems. In Turkey, the problems of the public hospitals' source are mainly lack of management and organization. And these management problems cause gaps at service quality and patient satisfaction. In most inpatient satisfaction researches, the dimensions such as satisfaction with health personnel, trust to health personnel, patient confidentiality, honesty of staff, providing courtesy information, hospital general cleaning and hotel services are discussed. The aim of this study is to evaluate the quality of inpatient treatment services of a public hospital according to the perceived satisfaction of inpatients and to present some suggestions. The population of the study is the inpatients in the public hospital. The study's data collection method involves interviewing with the inpatients, asking questions and using the secondary data. The obtained analyzed through statistical package program. The study included 164 inpatients in Nazilli public hospital in April 2018. According to the results of the study, there is a significant difference between the participants' perception of general care satisfaction and age groups and working status.
\end{abstract}

Keywords: Health Sector, Public Hospital, Health Services, Inpatient, Healthcare Management 


\section{Giriş}

Türkiye 80 milyonluk son derece dinamik nüfusuyla yaşamın her alanında sürekli bir dönüşüm halindedir. Sağlık hizmetleri de nüfusun bu dinamik yapısından nasibini almaktadır. Toplumun her yönüyle gelişmesi hastalarda geçmiş dönemlere kıyasla sağlık sektöründeki hizmet kalitesinde daha yüksek beklentilerin oluşmasına zemin hazırlamıştır. Bugün Türkiye'de sağlık hizmetlerinde ikili bir yapı mevcuttur. Ülkede şu anda kamu ve özel sektörde faaliyet gösteren çok sayıda kurum ve kuruluş bulunmaktadır. Sağlık hizmetlerinin önemli bir parçası olan hastanelerde de ikili bir yapı mevcuttur. Bu ikili yapı yani kamu ve özel hastaneleri yoğun bir rekabet ortamında hizmet vermektedirler. Bu durumda, hem kamu hem de özel sektöre ait hastanelerde tedavi hizmetlerinin kalitesi hastanelerin teknik donanımına ve insan kaynaklarına verilen öneme bağlı olacaktır.

Hastaneler sağlik sektöründe büyük bir yer kaplamaktadır ve bu nedenle, büyük işletmeler arasında değerlendirilmektedir. Bundan dolayı genel isletmeler gibi profesyonel yönetim ilkeleriyle yönetilmelidirler (Can ve İbicioğlu, 2008). Hastanelerin kamu veya özel olup olmaması profesyonel yönetimden ilkelerinden ayrı tutulmasını gerektirmez. Aksine daha fazla hasta çekme, gelen hastaları memnun etme ve hastanın ihtiyaç duyduğunda tekrar aynı hastaneyi tercih etmesini sağlama hastane yönetimlerinin temel sorunlarındandır (Rahman vd, 2008:96). Çünkü hastaların hastane seçme ve tercih etme olanakları son 10 yılda artmıştır. Sağlık sisteminde getirilen yeni düzenlemeler ve yatırımlar hasta memnuniyetinin artmasına zemin hazırlarken kurumlar arası rekabetin de yükselmesine olanak sağlamış görünmektedir. Fakat Türkiye'de hastanelerin en önemli sorunlarının başında yönetim sorunu, yani profesyonel yönetim anlayışının yetersiz olması gelmektedir (Can ve İbicioğlu, 2008, s.272).

Sağlık hizmetleri, insan yaşamı ile doğrudan ilişkilidir. Bu nedenle yönetim açısından özellikleri olan bir alandır. Koruyucu sağlık hizmetleri ile birinci basamak sağlık hizmetlerinin yönetiminde topluma yönelik ve sektörler arası işbirliğini gerektiren bir dizi yönetsel faaliyet gerekli iken, ikinci ve üçüncü basamak sağlık hizmetlerinin verildiği hastanelerde 
otelcilik hizmetlerinin yanı sıra, poliklinik, laboratuvar, röntgen ve ameliyathane hizmetleri gibi geniş bir yelpazede yönetim gerekliliği sağlık yöneticiliğini karmaşık hale getirmektedir (Çimen, 2010, s.136). Genel olarak bir tür sağlık kurumu olan hastanelerin de var olma amacına bakıldığında da "sağlık hizmeti" sunmak olduğu görülmektedir. Varlık nedeni sağlık hizmeti sunmak olan sağlık kurumlarından beklenen temel yetenek de, "nitelikli sağlık hizmeti sunabilmek" olmalıdır (Kıdak vd, 2015, s.487). Buna göre kaliteli sağlık hizmeti sunma ve çabası hastanelerin öncelikli hedefleri arasında yer almalıdır.

Kalite kavramı çok açık ve net olarak tanımlanamayan bir kavramdır. Bu nedenle yönetim biliminde bir görüş birliğinin olduğunu söylemek güçtür. Buna göre kalite bazı yönetim uzmanları tarafından "ürün ve hizmette hata ve yanlışların olmaması" şeklinde ele alınırken, kimi yönetim uzmanları da kaliteyi "bir mal veya hizmette mükemmeliyet derecesi" olarak tanımlamaktadırlar (Aktan, 2012:238). Günümüz zorlu pazar ortamında bir kurumun varlığını devam ettirebilmesi ve sürekli iş olanakları yaratabilmesi, kurumun kalite düzeyinin (ürün kalitesi, hizmet ve yönetim kalitesi vb) rekabetçi standartlara çekilmesiyle mümkün olabilmektedir. Kurumun içinde bulunduğu sektöre özgü standartları hayata geçirmesi müşteri memnuniyetini de beraberinde getirebilecektir (Oğuz, 2001, s.291).

Müşteri memnuniyeti, Pizam ve Ellis'e göre "Müşterinin bir mal ya da hizmetten umduğunu ya da beklediğini elde etmenin verdiği iyi hissetme veya hoşnutluğu ifade eden psikolojik bir kavram" iken Kotler ve Keller'e göre ise "Müşterinin satın alma öncesindeki beklentileri ile satın almadan sonraki algılanan performans arasındaki farka gösterdiği tepki" şeklindedir (aktaran: Cengiz Mutlubaş ve Soybalı, 2017, s.3). Buna göre müşteri memnuniyeti kavramı, müşterilerin istek, ihtiyaç ve beklentilerinin karşılanması ve bunların ötesine geçilmesini kapsayan bir kavram olarak karşımıza çıkmaktadır (Özgüven, 2008, s.657). Sağlık sektöründeki kurum ve kuruluşların da sağlik hizmetlerinde müşteri memnuniyetinin, uzun dönemde kalıc olma konusunda önemli bir belirleyici rolünün olduğunun bilincinde olmaları gerektiği söylenebilir. "Müşteri memnuniyeti" kavramı sağlık hizmetlerinde "hasta memnuniyeti" kavramına dönüşmektedir. 
"Hasta memnuniyeti" kavramı, sağllk hizmetlerinde kalite uygulamaları kapsamında son yıllarda önem kazanan ve oldukça fazla çalışılan bir konu durumundadır. Çünkü hastanın sunulan hizmet hakkındaki düşünceleri ve buna bağlı olarak memnuniyeti, hizmet kalitesinin değerlendirilmesinde önemlidir Hasta memnuniyeti, "hastanın değer ve beklentilerinin ne düzeyde karşılandığı konusunda bilgi veren ve esas otoritenin hasta olduğu bakımın kalitesini gösteren temel ölçüt" olarak tanımlanmaktadır (Türkuğur vd, 2016, s.170). Hasta memnuniyeti, hastaların aldıkları sağlık hizmeti veya tıbbi bakımla ilgili beklenti, deneyim ve değer yargıların ihtiva eden ve daha çok hastaların algılamalarına dayanan bir kavramdır. Algılanan hasta memnuniyeti boyutunda daha çok hastaların görüş ve değerlendirmeleri esas alınmaktadır. Bundan dolay algılanan hasta memnuniyeti, bakım kalitesine yönelik hasta perspektifi şeklinde nitelendirilmeye başlamıştır (Top vd, 2010, s.4).

Hasta memnuniyeti araştırmalarında sağlık personelinden ve iletişimden memnuniyet, personele güven, hasta mahremiyeti, personelin dürüstlüğü, nezaketi, yeterli bilgiyi sunması, hastane genel temizliği ve otelcilik hizmetleri gibi birçok boyutun ele alındığı görülmektedir (Türkuğur vd, 2016, s.170). Hasta memnuniyetinin hastane ve hastane çalışanlarıyla ilgili güvenilirlik, fiziksel görünüm ve isteklilik gibi unsurlardan etkilendiği Öcel (2016, s.74) tarafından yapılan bir araştırmada da açıkça ifade edilmiştir. Yılmaz (2001, s.73) 'a göre de hasta memnuniyeti, hizmetin sunumunu, hasta ile hizmeti verenlerin etkileşimini, hizmetin varlığını, hizmetin sürekliliğini, hizmeti verenlerin yeterliliği ve iletişim özelliklerini içeren çok boyutlu bir kavramdır. Bu açılardan bakıldığında hasta memnuniyetinin, hastanelerin sağlık bakım hizmetlerinin yapısı, süreci ve çıktısı hakkında önemli bilgiler ve değerlendirmelerin yapılmasına katkı sağladığı söylenebilir.

\section{Araştırmanın Amacı ve Yöntemi}

Türkiye'de tedavi edici sağlık hizmetleri üç basamak şeklinde gerçekleştirilmektedir. Bu basamaklar sırasıyla şu şekildedir (Milli Eğitim Bakanlığ1 [MEB], 2015, s.6):

- Birinci basamak tedavi hizmeti: Hastaların ilk başvurdukları, evde ve ayakta tedavi edildikleri kuruluşlardır. Aile hekimlikleri, 
toplum sağllğı merkezleri, kurum hekimlikleri birinci basamak tedavi hizmetlerinin verildiği yerlerdir. Birinci basamaktaki imkânlarla tam ve tedavisi yapılamayan hastalar ikinci basamağa sevk edilirler.

- İkinci basamak tedavi hizmeti: Hastaların yatırılarak tanı ve tedavi hizmetlerinin verildiği hastanelerdir. Hastalar uzmanlar tarafından tedavi edilirler.

- Üçüncü basamak tedavi hizmeti: Bu hizmetin verildiği yerler en üst düzeyde tıp teknolojisi kullanılan üniversite hastaneleri, kanser araştırma merkezleri, ruh ve sinir hastalıkları hastaneleri ve senatoryumlardır. Birinci ve ikinci basamakta sorunu çözülemeyen hastalar bu kuruluşlara sevk edilirler.

Çalışmanın sahası olan Nazilli'deki hizmet veren kamu hastanesi ikinci basamak sağlık hizmetlerinin verilebildiği genel hastaneler sınıfına dahil olan bir sağlık kurumudur. Çalışmanın amacı Nazilli Devlet Hastanesi'nde yatakta tedavi hizmetleri gören hastaların bakım memnuniyetlerini ve hizmet kalitesini değerlendirmek ve bazı öneriler sunabilmektir. Bu amaçla Sağlık Hizmetleri Genel Müdürlüğü Sağlıkta Kalite ve Akreditasyon Daire Başkanlığı tarafından hazırlanan "Yatan Hasta Memnuniyet Anketi" temel alınmıştır. Anketteki toplam 26 sorununun 10'u yatan hastaların demografik özelliklerini belirlemek ve diğer 16 soru yatan hastaların memnuniyetlerinin algılanmasına yönelik 5'li likert tipi sorulardan oluşmaktadır. Anketteki 5'li likert tipi soruların yatan hastalar tarafindan, 1 "Kesinlikle Katılmıyorum", 2 "Katılmıyorum", 3 "Karasızım", 4 "Katılıyorum" ve 5 "Kesinlikle Katılıyorum" şeklinde yanitlanması istenmiştir. Anket formu Nazilli Devlet Hastanesi'nde $9 \mathrm{Ni}$ san 2018 - 22 Nisan 2018 tarihlerinde hizmet alan 164 yatan hastaya uygulanmıştır. Elde edilen veriler istatistik paket programı ile değerlendirilmiştir.

Güvenilirlik analizinde Cronbach Alfa katsayısından yararlanılmıştır. Katsayının yorumlanması şu şekildedir (Kalaycı, 2008:405):

[1] $0.00 \leq \ldots<0.40$ ölçek güvenilir değil,

[2] $0.40 \leq \ldots<0.60$ ölçek güvenilirliği düşük,

[3] $0.60 \leq \ldots<0.80$ ölçek güvenilir ve

[4] $0.80 \leq \ldots<1$ ölçek yüksek derecede güvenilirdir. Çalışmanın güvenilirlik düzeyi Cronbach's Alpha= 0,78 olarak tespit edilmiş olup 
güvenilir düzeyde bulunmuştur. Verilerin değerlendirilmesinde tanımlayıcı istatistikler kullanılmıştır.

Araştırmadan elde edilen veriler istatistik paket programı kullanılarak analiz edilmiştir. Verilerin analizinde uygun analiz türünün belirlenmesi aşamasında ( $\mathrm{n}=164)$, verilerinin normal dağılım gösterip göstermediği, homojen bir yapıya sahip olup olmadıkları incelenmiştir. Verilerin normal dağılımının tespitine yönelik yapılan analiz sonucuna göre (Test of Normality) verilerin Skewness ve Kurtosis değerlerinin +1.5 ile -1.5 aralığında olduğu tespit edilmiş, (Skewness -0.874 ve Kurtosis 0.461 ) tüm bu bulgular sonucunda parametrik analiz yöntemleri tercih edilmiştir (Tabachnick ve Fidell 2013:6). Verilerin analizinde frekans ve yüzde dağılımı, aritmetik ortalama ve standart sapma, parametrik ve parametrik olmayan testler kullanılmıştır. Araştırmada anlamlılık düzeyi olarak 0.05 düzeyi kabul edilmiştir.

Yatan hastaların bakım memnuniyetlerinin değerlendirilmesine yönelik çeşitli araştırmalar mevcuttur. Bunlardan bazılarına kısaca değinilmiştir. Çin'de Chen ve ekibi (2016) tarafından yapılan bir araştırmada yatan hastaların büyük bir kısmı hastanede verilen hizmetlerden oldukça memnun kaldığını belirtmiştir. Yine aynı araştırmaya göre yatan hastaların cinsiyetleri, meslekleri, ve yaşları genel bakım memnuniyetlerinin düzeylerini etkilerken; aylık gelirleri ve evlilik durumları etkilememektedir. Thi ve ekibi tarafından 2002 yılında yapılan diğer bir araştırmanın sonuçlarına göre yaşlı hastalar kendilerine verilen genel bakım hizmetlerinden daha fazla memnun kalma eğilimindedir. Ayrıca erkekler kadınlara göre daha fazla memnun kalmaktadır. Türkuğur ve ekibi (2016) yatan hastaların memnuniyeti konusunda yaptıkları araştırmada kadınların erkeklere göre memnuniyet düzeyleri daha yüksek çıkmıştır. Araştırmaya göre katılımcıların yaşları, öğrenim düzeyleri ve sosyal güvence durumları ile genel memnuniyet düzeyleri arasında anlamlı farklılık vardır. Yine Tükel ve arkadaşları (2004) tarafından yapılan bir araştırmada yatan hasta memnuniyetinin hastaları yaş grupları ve öğrenim düzeylerine göre istatistiksel olarak anlamlı farklılık bulunmuştur. Buna karşın aynı araştırmaya göre yatan hastaların cinsiyet ve gelir durumlarına göre istatiksel açıdan anlamlı bir farklılık bulunmamıştır. Bütün bunlardan hareketle araştırmanın hipotezleri şu şekilde belirlenmiştir: 
H1: Yatan hastaların genel bakım memnuniyet algısı cinsiyete göre anlamlı farklılık göstermektedir.

H2: Yatan hastaların genel bakım memnuniyeti algısı yaş gruplarına göre anlamlı farklılık göstermektedir.

H3: Yatan hastaların genel bakım memnuniyeti algısı medeni durumlarına göre anlamlı farklılık göstermektedir.

H4: Yatan hastaların genel bakım memnuniyeti algısı başvuru durumlarına göre anlamlı farklılık göstermektedir.

H5: Yatan hastaların genel bakım memnuniyeti algısı yatış sürelerine göre anlamlı farklılık göstermektedir.

H6: Yatan hastaların genel bakım memnuniyeti algısı çalışma durumlarına göre anlamlı farklılık göstermektedir.

H7: Yatan hastaların genel bakım memnuniyeti algısı eğitim durumlarına göre anlamlı farkl1l1k göstermektedir.

\section{Araştırmanın Bulguları ve Değerlendirmeler}

Bu bölümde Nazilli Devlet Hastanesi'nde yatan hastalara yönelik yapılan araştırmanın bulguları ve değerlendirmeleri yapılmıştır.

\subsection{Demografik Özelliklere İlişkin Bulgular}

Tablo 1. Yatan Hastalarn Demografik Özellikleri

\begin{tabular}{lcc}
\hline Cinsiyet & Frekans & Yüzde \\
\hline Erkek & 79 & 48,2 \\
\hline Kadın & 85 & 51,8 \\
\hline Yaş Aralı̆̆ı & & \\
\hline $18-59$ Yaş Aralığı & 84 & 48,2 \\
\hline 60 Yaş ve üzeri & 80 & \\
\hline Medeni Durum & & 81,1 \\
\hline Evli & 133 & 18,9 \\
\hline Bekar & 31 & 20,1 \\
\hline Öğrenim Düzeyi & & 11,6 \\
\hline Okur-Yazar Değil & 33 & 42,7 \\
\hline Okur-Yazar & 19 & 9,8 \\
\hline İlkokul & 70 & 9,1 \\
\hline Ortaokul & 16 & 6,7 \\
\hline Lise ve Dengi Okul & 15 & \\
\hline Üniversite ve Üstü & 11 & 35,4 \\
\hline Hastaneye İlk Başvurumu Durumu & & 64,6 \\
\hline Evet & 58 & \\
\hline Hayır & 106 & \\
\hline
\end{tabular}




\begin{tabular}{lcc} 
Hasta Yatış Süresi & & \\
\hline $1-3$ gün & 45 & 27,4 \\
\hline $4-6$ gün & 50 & 30,5 \\
\hline $7-9$ gün & 28 & 17,1 \\
\hline 10 gün ve üzeri & 41 & 25,0 \\
\hline Sosyal Güvence & 29 & 17,7 \\
\hline SGK Çalışan & 63 & 38,4 \\
\hline SGK Emekli & 19 & 11,6 \\
\hline Yeşil Kart & 3 & 1,8 \\
\hline Özel Sağlık Sigortası & 6 & 3,7 \\
\hline Sosyal Güvence Yok & 44 & 26,8 \\
\hline Diğer & & \\
\hline Çalışma Durumu & 11 \\
\hline Özel Sektör Çalışanı & 18 & 8,5 \\
\hline Kamu Çalışanı & 14 & 8,5 \\
\hline Serbest Meslek & 14 & 33,5 \\
\hline Emekli & 55 & 31,1 \\
\hline İşsiz & 51 & 7,3 \\
\hline Diğger & 12 &
\end{tabular}

Ankete 170 yatan hasta katılmıştır. 6 anket kısmen hatalı bulunduğu için çalışmaya 164 anket dahil edilmiştir. Anket verilerine göre katılımcların \%48,2'si erkek ve \%51,8'i ise kadındır. Katılımcıların $\% 52,2$ 'si ise 18-59 yaş aralığındadır. Katılımcılar arasında öğrenim durumu açısından en yüksek oranı ilkokul mezunları oluştururken üniversite mezunları en az orana sahiptir.

\subsection{Anket Soruları ve Hipotezlere İlişkin Bulgular}

Araştırmada kullanılan ölçekte katılımcların bakım memnuniyetlerini analiz etmeye yönelik 16 adet 5'li likert tipi sorular bulunmaktadır. Tablo 2'ye göre ilk dört soru hasta odasının durumu, 5'inci ve 6'ınc sorular yemeklerin durumu, 7'inci ve 8'inci sorular doktorların hastalara karşı tavrı, 9'uncu ve 10'uncu sorular hemşirelerin hastalara karşı tutumu, 11'inci soru personellerin genel tavrı, 12'inci soru temizlik personelin hastalara karşı tavrı ve son dört soru da hastanenin durumu ile ilgilidir.

Ankete katılan yatan hastaların anket sorularına verdikleri yanıtlar 1 ile 5 arasında değerlendirildiğinde en yüksek ortalamanın "Doktorlar bana karşı kibar ve saygilıydı." ifadesine ait olduğu (ortalama: 4,616) 
görülmektedir. Buna karşıllk en düşük ortalamaya sahip ifadenin ise "Yemekler lezzetliydi." olduğu anlaşılmaktadır.

Tablo 2. Katılımcılarn Anket Sorularna Verdikleri Yanıtlarn Ortalamaları

\begin{tabular}{|c|c|c|c|c|}
\hline & Anket Soruları & $\overline{\bar{X}}$ & $\begin{array}{c}\text { Std. } \\
\text { Sapma }\end{array}$ & $\mathbf{N}$ \\
\hline 1 & Yattı̆̆ım oda temizdi. & 4,610 & 0,612 & 164 \\
\hline 2 & Oda sicaklığı uygundu. & 4,512 & 0,713 & 164 \\
\hline 3 & Yattığım oda ve çevresi gürültülü değildi. & 4,201 & 0,986 & 164 \\
\hline 4 & $\begin{array}{l}\text { Odadaki eşyalar çalışır durumdaydı ( hemşire çağrı } \\
\text { zili, lamba, yatak vb.). }\end{array}$ & 4,573 & 0,627 & 164 \\
\hline 5 & Yemekler geldiğinde sıcaktı. & 4,262 & 0,835 & 164 \\
\hline 6 & Yemekler lezzetliydi. & 4,043 & 0,980 & 164 \\
\hline 7 & $\begin{array}{l}\text { Doktorlar hastalığım konusunda bana bilgi verdi ve } \\
\text { zaman ayırdı. }\end{array}$ & 4,512 & 0,687 & 164 \\
\hline 8 & Doktorlar bana karşı kibar ve saygılıydı. & 4,616 & 0,640 & 164 \\
\hline 9 & Hemşireler bana karşı kibar ve saygılıydı. & 4,390 & 0,882 & 164 \\
\hline 10 & $\begin{array}{l}\text { Hemşireler yapacakları işlemler (ateş-tansiyon } \\
\text { ölçme, kan alma, ilaç verme vb.) hakkında bilgi ver- } \\
\text { diler. }\end{array}$ & 4,372 & 0,837 & 164 \\
\hline 11 & $\begin{array}{l}\text { Tüm personel kişisel mahremiyetime (muayene } \\
\text { edilirken kapının kapanması, aradaki perde ya da } \\
\text { paravanın çekilmesi gibi) özen gösterdi. }\end{array}$ & 4,451 & 0,778 & 164 \\
\hline 12 & Temizlik personeli bana karşı kibar ve saygıllydı. & 4,415 & 0,879 & 164 \\
\hline 13 & Bu hastane güvenlidir. & 4,561 & 0,728 & 164 \\
\hline 14 & Bu hastaneyi başkalarına tavsiye ederim. & 4,500 & 0,669 & 164 \\
\hline 15 & Hastane genel olarak temizdi. & 4,518 & 0,696 & 164 \\
\hline \multirow[t]{2}{*}{16} & Hastanede verilen hizmet genel olarak iyiydi. & 4,500 & 0,669 & 164 \\
\hline & Genel Memnuniyet Algisı & 4,440 & 0,502 & 164 \\
\hline
\end{tabular}

Anketin genel bakım memnuniyeti alg1 düzeyi ise 4,440 olarak gerçekleşmiştir. Bu durumda yatan hastaların genel bakım memnuniyeti algisının oldukça yüksek düzeyde olduğu söylenebilir.

Tablo 3. Yatan Hastaların Bakım Memnuniyeti Algısının Cinsiyete Göre Bă̆ımsız T-Testi

\begin{tabular}{llllllll}
\hline & Cinsiyet & $\mathbf{N}$ & $\overline{\boldsymbol{X}}$ & Ss & Sd & $\mathbf{t}$ & $\mathbf{p}$ \\
\hline $\begin{array}{l}\text { Genel Bakım } \\
\text { Memnuniyeti } \\
\text { Alg1S1 }\end{array}$ & Kadın & 85 & 4,38 & 0,508 & 162 & $-1,605$ & 0,110 \\
\cline { 2 - 5 } & Erkek & 79 & 4,50 & 0,491 & & & \\
\hline
\end{tabular}

Yatan hastaların genel bakım memnuniyet algısının cinsiyete göre 
farklılaşıp farklılaşmadığını belirlemek amacıyla bağımsız t-testi analizi uygulanmıştır. Tablo 3'e göre katılımcıların cinsiyetleri ile genel bakım memnuniyeti algısı arasında anlamlı bir farklılığa rastlanmamıştır $(\mathrm{p}=0,110 ; \mathrm{p}>0,05)$. H1 desteklenmemiştir.

Tablo 4. Yatan Hastaların Bakım Memnuniyeti Algısının Yaş Gruplarına Göre Bă̆ımsız T-Testi

\begin{tabular}{|c|c|c|c|c|c|c|c|}
\hline & Yaș Grupları & $\mathbf{N}$ & $\bar{X}$ & Ss & Sd & $\mathbf{t}$ & p \\
\hline Genel Bakım & 18-59 Yaş Arası & 84 & 4,34 & 0,564 & 151,140 & $-2,613$ & 0,010 \\
\hline $\begin{array}{l}\text { Memnuniyeti } \\
\text { Alg1S1 }\end{array}$ & 60 Yaş ve Üzeri & 80 & 4,54 & 0,407 & & & \\
\hline
\end{tabular}

Yatan hastaların genel bakım memnuniyet algısının yaş gruplarına göre farklılaşıp farklılaşmadığını belirlemek amacıyla bağımsız t-testi analizi uygulanmıştır. Tablo 4'e göre katılımcların yaş grupları ile genel bakım memnuniyeti algısı arasında anlamlı bir farklılığa rastlanmıştır $(\mathrm{p}=0,010 ; \mathrm{p}<0,05)$. H2 desteklenmiştir. Buna göre $18-59$ yaş arası gruba dahil olan katılımcılar, 60 yaş ve üzeri olanlara kıyasla daha düşük genel bakım memnuniyet algısına sahiptirler.

Tablo 5. Yatan Hastalarn Bakım Memnuniyeti Algısının Medeni Durumlarna Göre Bă̆ımsız T-Testi

\begin{tabular}{lllrlrll}
\hline & Medeni Durumu & $\mathbf{N}$ & $\overline{\boldsymbol{X}}$ & $\mathbf{S s}$ & Sd & $\mathbf{t}$ & $\mathbf{p}$ \\
\hline $\begin{array}{l}\text { Genel Bakım } \\
\begin{array}{l}\text { Memnuni- } \\
\text { yeti Algisi }\end{array}\end{array}$ & Evli & 133 & 4,434 & 0,512 & 162 & $-0,294$ & 0,769 \\
\cline { 2 - 5 } & Bekar & 31 & 4,464 & 0,455 & & & \\
\hline
\end{tabular}

Yatan hastaların genel bakım memnuniyet algisının medeni durumlarına göre farklılaşıp farklılaşmadığını belirlemek amacıyla bağımsız t-testi analizi uygulanmıştır. Tablo 5'e göre katılımcıların medeni durumları ile genel bakım memnuniyeti algısı arasında anlamlı bir farklılığa rastlanmamıştır ( $p=0,769 ; p>0,05)$. H3 desteklenmemiştir.

Tablo 6. Yatan Hastaların Bakım Memnuniyeti Algısının Başvuru Durumlarına Göre Bă̆ımsız T-Testi

\begin{tabular}{llllllll}
\hline Genel Bakım & Başvuru Durumu & $\mathbf{N}$ & $\overline{\boldsymbol{X}}$ & Ss & Sd & $\mathbf{t}$ & $\mathbf{p}$ \\
\cline { 2 - 6 } $\begin{array}{l}\text { Memnuniyeti Al- } \\
\text { g1si }\end{array}$ & Evet & 58 & 4,403 & 0,500 & 162 & $-0,693$ & 0,490 \\
\cline { 2 - 6 } & Hayır & 106 & 4,456 & 0,499 & & & \\
\hline
\end{tabular}


Yatan hastaların genel bakım memnuniyet algısının başvuru durumlarına göre farklılaşıp farklılaşmadığını belirlemek amacıyla bağımsız t-testi analizi uygulanmıştır. Tablo 6'ya göre katılımcıların başvuru durumları ile genel bakım memnuniyeti algısı arasında anlamlı bir farklılığa rastlanmamıştır ( $p=0,490 ; p>0,05)$. H4 desteklenmemiştir.

Tablo 7. Yatan Hastaların Bakım Memnuniyeti Algısının Yatış Sürelerine Göre Tek Yönlï Anova Testi

\begin{tabular}{lllllll}
\hline & Yatıs Süresi & $\mathbf{N}$ & $\overline{\boldsymbol{X}}$ & Ss & $\mathbf{F}$ & $\mathbf{p}$ \\
\hline Genel Bakım & 1-3 gün & 45 & 4,382 & 0,0833 & \multirow{2}{*}{1,213} & 0,307 \\
\cline { 2 - 5 } $\begin{array}{l}\text { Memnuniyeti } \\
\text { Alg1S1 }\end{array}$ & 4-6 gün & 50 & 4,389 & 0,0711 & & \\
\cline { 2 - 5 } & 7-9 gün & 28 & 4,442 & 0,0894 & & \\
\cline { 2 - 5 } & 10 gün ve üzeri & 41 & 4,564 & 0,0700 & & \\
\hline Toplam & & 164 & 4,440 & 0,0392 & & \\
\hline
\end{tabular}

Tablo 7'de görüldüğü gibi yatan hastaların genel bakım memnuniyeti algısının hastanede yatış sürelerine ilişkin tek yönlü anova testi uygulanmıştır ve anlamlı bir farklılığa rastlanmamıştır $(\mathrm{F}=1,123, \mathrm{p}=0,307$, $\mathrm{p}<0,05)$. H5 desteklenmemiştir.

Tablo 8. Yatan Hastaların Bakım Memnuniyeti Algısının Çalışma Durumlarına Göre Kruskal Wallis Testi

\begin{tabular}{|c|c|c|c|c|c|c|c|c|}
\hline Değişkenler & $\begin{array}{l}\text { Çalışma } \\
\text { rumu }\end{array}$ & Du- & $\mathbf{N}$ & $\overline{\bar{X}}$ & Sira Ort. & Sd & Ki Kare & $p$ \\
\hline \multirow{7}{*}{$\begin{array}{l}\text { Genel Bakım } \\
\text { Memnuni- } \\
\text { yeti Algisı }\end{array}$} & Özel & Sektör & 18 & 4,115 & 58,56 & \multirow[t]{7}{*}{5} & \multirow[t]{7}{*}{19,622} & \multirow[t]{7}{*}{0,001} \\
\hline & Çalışanı & & & & & & & \\
\hline & Kamu Ça & lişanı & 14 & 4,335 & 77,25 & & & \\
\hline & Serbest $\mathrm{N}$ & Teslek & 14 & 4,388 & 78,11 & & & \\
\hline & Emekli & & 55 & 4,361 & 71,41 & & & \\
\hline & İşsiz & & 51 & 4,600 & 97,17 & & & \\
\hline & Diğer & & 12 & 4,792 & 118,17 & & & \\
\hline
\end{tabular}

Yatan hastaların genel bakım memnuniyeti algı düzeylerinin çalışma durumlarına göre farklılaşıp farklılaşmadığını belirlemek için Kruskal Wallis testi uygulanmıştır. Bulgular Tablo 8'de verilmiştir. Yapılan Kruskal Wallis testi bulgularına göre yatan hastaların genel memnuniyet alg1 düzeylerinin çalışma durumlarına göre kısmen anlamlı farklılık taşıdığ 1 anlaşılmaktadır $\quad(x 2(5)=19,622 ; \quad \mathrm{p}=0,001 ; \quad \mathrm{p}<0,05) . \quad$ H6 $\quad$ k1smen 
desteklenmiştir. Gruplar arasındaki farkl1lıkların belirlenmesi için Bonferroni testleri yapılmıştır. Buna göre anlamlı farklılı̆̆ının kaynağının yatan hastalardan özel sektör çalışanları ile işsiz olanlar ve diğerleri arasında olduğu (sırasılyla $\mathrm{p}=0,004$ ve $\mathrm{p}=003 ; \mathrm{p}<0,05$ ) belirlenmiştir.

Tablo 9. Yatan Hastaların Bakım Memnuniyeti Algısının Ĕ̆itim Durumlarına Göre Kruskal Wallis Testi

\begin{tabular}{|c|c|c|c|c|c|c|}
\hline Değişkenler & Eğitim Durumu & $\mathbf{N}$ & $\begin{array}{l}\text { Sira } \\
\text { Ortalaması }\end{array}$ & Sd & Ki Kare & p \\
\hline \multirow{6}{*}{$\begin{array}{l}\text { Genel Bakım } \\
\text { Memnuniyeti } \\
\text { Algısı }\end{array}$} & Okur-yazar değil & 33 & 95,52 & \multirow[t]{6}{*}{5} & \multirow[t]{6}{*}{7,421} & \multirow[t]{6}{*}{0,191} \\
\hline & Okur-yazar & 19 & 74,13 & & & \\
\hline & İlkokul & 70 & 86,43 & & & \\
\hline & Ortaokul & 16 & 61,81 & & & \\
\hline & Lise & 15 & 73,63 & & & \\
\hline & Üniversite & 11 & 75,09 & & & \\
\hline Toplam & & 164 & & & & \\
\hline
\end{tabular}

Yatan hastaların genel bakım memnuniyeti algı düzeylerinin eğitim durumlarına göre farklılaşıp farklılaşmadığını belirlemek için Kruskal Wallis testi uygulanmıştır. Bulgular Tablo 9'da verilmiştir. Yapılan Kruskal Wallis testi bulgularına göre yatan hastaların genel memnuniyet alg1 düzeylerinin eğitim durumlarına göre anlamlı farklılık taşımadığı anlaş1lmaktadır $(x 2(5)=7,421 ; p=0,191 ; p>0,05)$. H7 desteklenmemiştir.

\section{Sonuç ve Öneriler}

Bu çalışma Aydın iline bağlı Nazilli ilçesindeki kamu hastanesinde Mart 2018'de iki haftalık süreçte gerçekleştirilmiştir. Çeşitli servislerde tedavi olan ve yatan hastaların 164'ü çalışmaya katılımı sağlanmıştır. Çalışmada katılımcların hastanelerinden memnuniyet düzeyleri ve demografik özelliklerine göre genel bakım memnuniyet algılarının farklılık gösterip göstermediğinin tespiti amaçlanmıştır.

Çalışmanın bulgularına göre yatan hastalar Nazilli Kamu Hastanesi'nde verilen hizmetlerden oldukça memnundur. Bu hizmetler kısaca odaların temizliği ve konforu, yemeklerin kalitesi, kişisel mahremiyete verilen önem, doktorların, hemşirelerin ve temizlik personelinin ilgisi şeklinde belirlenmiştir. 
Yatan hastaların genel bakım memnuniyeti algısı ile cinsiyeti, medeni durumları, başvuru durumları, yatış süreleri ve eğitim durumları arasında anlamlı farklılık bulunmamıştır. Buna karşılık katılımcıların genel bakım memnuniyeti algısı ile yaş grupları ve çalışma durumları arasında anlamlı farklılık bulunmuştur. Çalışmaya göre ileri yaştaki hastaların memnuniyet düzeyleri diğer hastalara kıyasla çok daha yüksektir. Bu gruptaki hastaların geçmiş tecrübeleri olumlu bir değerlendirme yapmış olmalarına neden olabilir. Çünkü 2000'li yıllardan itibaren sağlık alanında yaşanan pozitif dönüşümler bu kişiler tarafından gözlenmiştir. Nazilli'deki kamu hastanesi de yeni hizmete girmiş ve modern bir yapılanmaya sahip olduğu söylenebilir. Katılımcılar arasında en düşük genel memnuniyet algısına sahip olanlar özel sektör çalışanları iken; işsiz olanlar ve diğerleri (evhanımları vs.) en yüksek algıya sahiptir.

Sonuç olarak çalışmanın uygulandığı hastanenin yatan hasta hizmetleri katılımcılar tarafından oldukça yeterli bulunmuştur. 18-59 yaş aralığındaki yatan hastaların ve özel sektör çalışanlarının hizmet kalitesine ilişkin beklentilerinin belirlenmesi için yeni çalışmalar yapılabilir. Ayrıca hizmet kalitesini artırabilmek için hastane ekipmanları ve çalışanları konusunda da daha farklı projeler geliştirilebilir. Böylece yapılacak iyileştirmelere bağlı olarak hastanenin yatan hastalarla ilgili hizmet kalitesinde de belirgin artışlar yaşanabilecektir. 


\title{
EXTENDED ABSTRACT
}

\section{Healthcare Satisfaction Evaulations of Inpatients: A Practice in Public Hospital}

\author{
Çağrı Köroğlu - Hüseyin Önlem Ersöz - Aslı Çayan - Sultan Kılıç \\ Aydın Adnan Menderes University
}

The health sector in Turkey has been rapidly changing and growing. It has become a necessity for hospitals, which is an important part of the healthcare sector, to be managed according to the circumstances of the day. Because the importance of health given by all segments of society in Turkey has been raising, day by day. Although this helps to increase the quality of the health care services of the hospitals, it also brings with it a number of problems. There is a dual structure (public and private sector) in the health care sector Turkey. The new regulations and investments in the health system provided the basis for increasing patient satisfaction. This situation caused the competition of public and private hospitals to rise. In Turkey, the problems of the public hospitals' source are mainly lack of management and organization. And these management problems cause gaps at service quality and patient satisfaction. In recent years, the concept of patient satisfaction is a matter of importance in health services within the scope of quality practices. Patient satisfaction gives information about the level of patient's values and expectations. The main decisionmaking authority here is the patient, himself and this is a kind of a measure of service quality. In most inpatient satisfaction researches, the dimensions such as satisfaction with health personnel, trust to health personnel, patient confidentiality, honesty of staff, providing courtesy information, hospital general cleaning and hotel services are discussed.

The public hospital in Nazilli, where is the area of the study, is a health institution that is included in the general hospitals class where secondary health care services (where patients and inpatients are treated by regular doctors) can be provided. The aim of this study is to evaluate the quality of inpatient treatment services of The Nazilli Puclic Hospital according to the perceived satisfaction of inpatients and to present some suggestions. 
The population of the study is the inpatients in the public hospital. The study's data collection method involves interviewing with the inpatients, asking questions and using the secondary data. 10 of the total 26 questions in the questionnaire were used to determine the demographic characteristics of inpatients. The remaining 16 questions consisted of 5-point Likerttype questions to detect the satisfaction of inpatients. The obtained analyzed through statistical package program. The study included 164 inpatients in Nazilli public hospital in April 2018. The reliability of the study was determined as Cronbach's Alpha and it was 0.78. This result was found to be reliable. In this search descriptive statistics were used to evaluate the data. According to the results of the analysis conducted to determine the normal distribution of data, Skewness and Kurtosis values of the data were found to be between +1.5 and -1.5 (Skewness -0.874 and Kurtosis 0.461 ). As a result of all these findings, in some anlaysis the parametric analysis methods were preferred. The level of significance of hypothesis tests was accepted as 0.05 .

The hypotheses of the research were determined as follows:

- H1: The perception of general care satisfaction of inpatients varies significantly by gender,

- H2: The perception of general care satisfaction of inpatients shows a significant difference according to age groups,

- H3: The perception of general care satisfaction of inpatients varies significantly according to their marital status,

- H4: The perception of general care satisfaction of inpatients varies significantly according to their application status,

- H5: The perception of general care satisfaction of inpatients shows a significant difference according to their hospitalization periods,

- H6: The perception of general care satisfaction of inpatients shows a significant difference according to their working status,

- H7: The perception of general care satisfaction of inpatients shows a significant difference according to their educational status.

According to the findings of the study, inpatients are very satisfied with the services provided in Nazilli Public Hospital. These services are briefly defined as the general care satisfaction, gender, marital status, admission times, hospitalization periods and educational status of inpatients. On the other hand, there were significant differences between the 
perception of general care satisfaction of the participants and participants' age groups and their working status. Past experiences of inpatients in this group may cause them to have a positive assessment. Private sector employees have the lowest overall satisfaction perception among the participants. Unemployed inpatients and others (housewives, etc.) have the highest perceptions. As a result, inpatient services of the hospital where the study was performed were found to be quite sufficient by the participants. In order to improve the service cleanliness and comfort of the rooms, the quality of the food, the importance given to personal privacy, the interest of doctors, nurses and cleaning staffs. There was no significant difference between the perception of quality, different projects can be developed on hospital equipments and employees. Thus, depending on the improvements to be made, there may be significant increases in the service quality of hospital inpatients.

\section{Kaynakça / References}

Aktan C. C. (2012). Organizasyonlarda toplam kalite yönetimi. Organizasyon ve Yönetim Bilimleri Dergisi, 4(2), 237-262

Can A. ve İbicioğlu H. (2008). Yönetim ve yöneticilik yönünden üniversite hastanelerinin değerlendirilmesi. Süleyman Demirel Üniversitesi $I_{k} k$ tisadi Ve İdari Bilimler Fakültesi Dergisi, 13(3), 253-275

Cengiz Mutlubaş I. ve Soybalı H. H., (2017). Müşteri memnuniyetini oluşturan faktörlerin müşteri sadakatine etkisinin lojistik regresyon analizi ile incelenmesi. Türk Turizm Araştırmaları Dergisi, 1(3), 1-15.

Chen H., Li M., Wang J., Xue C., Ding T., Nong X., Liu Y. ve Zhang L. (2016). Factors influencing inpatients' satisfaction hospitalization service in public hospitals in Shanghai. People's Republic of China, Patient Preference and Adherence, 10, 469-477

Çimen M. (2010). Sağlık yönetimi ve sağlık yönetimi eğitimi. Acıbadem Üniversitesi Sağlık Bilimleri Dergisi, 1(3), 136-139

Kalaycı, Ş. (2008). SPSS uygulamalı çok değişkenli istatistik teknikleri, 3. Baskı, Ankara: Asil Yayınevi.

Kıdak L. B., Nişancı Z. N. ve Burmaoğlu S. (2015). Sağlık hizmetlerinde kalite ölçümü: Kamu hastanesi örneği. Celal Bayar Üniversitesi I.İ.B.F., Yönetim ve Ekonomi Dergisi, 22(2), 483-500 
Oğuz T. (2001). İstatiksel kalite kontrolu yönetim metodolojisine dönüştüren kalite gurusu: W. Edwards Deming. Kurgu Dergisi, 18, 279-293

Öcel Y. (2016). Sağlık hizmet kalitesinin müşteri memnuniyeti üzerine etkisi: Bolu ve Düzce örneği. Düzce Üniversitesi sosyal Bilimler Enstitüsü Dergisi, 6(1), 56-79.

Özgüven N. (2008). Hizmet pazarlamasında müşteri memnuniyeti ve ulaştırma sektörü üzerinde bir uygulama. Ege Akademik Bakış Dergisi, 8(2), 651-682

Rahman S., Demirel B., Firat G., Kırmızıgül Ş., Kubat C. (2008). Hasta

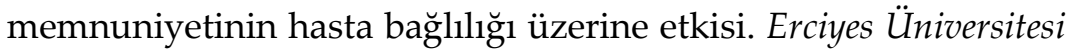
İktisadi ve İdari Bilimler Fakültesi Dergisi, 31, 95-110

Tabachnick, B. G. and Fidell, L. S. (2013). Using multivariate statistics. Boston: Pearson.

Thi P. L. N., Briançon S., Empereur F. ve Guillemin F. (2002). Factors determining .npatient satisfaction with care. Social Science $\mathcal{E}$ Medicine, 54(4), 493-504

Top M., Tarcan M., Güler H., Tekingündüz S. (2010). Hastane sektöründe yatan hastaların hasta tatmini ve hastane kalitesi algılamalarının değerlendirilmesi: İzmir ili sağlık bakanlığı hastaneleri örneği, İktisat ve girişimcilik üniversitesi, Türk dünyası Kırgız-Türk sosyal bilimler enstitüsü. Akademik Bakış Dergisi, 22, 1-29

Tükel B., Acuner A. M., Önder Ö. R. ve Üzgül A. (2004). Ankara Üniversitesi İbn-i Sina Hastanesi'nde yatan hasta memnuniyeti (Cerrahi Anabilim Dalı Örneği). Ankara Üniversitesi Tıp Fakültesi Mecmuası, 57(4), 205-214

Türkuğur Ü., Alıcı B., Uzuntarla Y., Güleç M. (2016). Yatan hasta memnuniyetinin incelenmesi: Bir eğitim hastanesi örneği. Gülhane Askeri Tip Akademisi Dergisi, 58, 170-173

Milli Eğitim Bakanlığı [MEB], (2015). Sağlık hizmetleri ve personel yönetimi. http://www.megep.meb.gov.tr/mte_program_modul/moduller_pdf/Sa$\%$ C4\%9Fl\%C4\%B1k\%20Kurumlar\%C4\%B1\%20Ve\%20Personel\%20Y\%C3\%B6netimi.pdf adresinden 15.01.2019 tarihinde erişilmiştir.

Yılmaz M. (2001). Sağlık bakım kalitesinin bir ölçütü: Hasta memnuniyeti. Cumhuriyet Üniversitesi Hemşirelik Yüksekokulu Dergisi, 5(2), 69-74 


\section{Kaynakça Bilgisi / Citation Information}

Köroğlu, Ç, Ersöz, H. Ö, Çayan, A. ve Kılıç, S. (2019). Yatan hastaların bakım memnuniyetlerinin değerlendirilmesi: Kamu hastanesinde bir uygulama. OPUS-Uluslararası Toplum Araştırmaları Dergisi , 10(17), 677-695. DOI: 10.26466/opus.519588 